Research Article

\title{
The Diurnal Variations of GPS PWV near Poyang Lake in China during Midsummer
}

\author{
Shanshan $\mathrm{Wu},{ }^{1}$ Haibo Zou $\mathbb{D}^{2},{ }^{2}$ and Junjie $\mathrm{Wu}^{3}$ \\ ${ }^{1}$ Jiangxi Climate Center, Nanchang 330096, China \\ ${ }^{2}$ Meteorological Sciences Institute of Jiangxi Province, Nanchang 330096, China \\ ${ }^{3}$ Civil Aviation Flight University of China, Guanghan 618307, China \\ Correspondence should be addressed to Haibo Zou; zouhaibobo@sohu.com
}

Received 9 December 2019; Revised 7 April 2020; Accepted 30 June 2020; Published 21 July 2020

Academic Editor: Stefania Bonafoni

Copyright (C) 2020 Shanshan Wu et al. This is an open access article distributed under the Creative Commons Attribution License, which permits unrestricted use, distribution, and reproduction in any medium, provided the original work is properly cited.

With the $1 \mathrm{~h}$-averaged data of atmospheric precipitable water vapor (PWV) for 2015-2018 retrieved from 18 ground-based Global Positioning System (GPS) observation stations near Poyang Lake (PL), China, the diurnal variations of the PWV during midsummer (July-August) are studied by the harmonic method. Results show that significant diurnal variations of PWV are found at the 18 GPS stations. The harmonics with $24 \mathrm{~h}$ cycle (diurnal cycle) over PL (i.e., Duchang and Poyang) and Nanchang city only have about $50 \%$ (or even smaller than $50 \%$ ) of variance contribution with the amplitude of about $0.2 \mathrm{~mm}$, while above $70 \%$ (or even $80 \%$ ) of variance contribution occurs elsewhere around PL, with the amplitude of about $0.9 \mathrm{~mm}$. The harmonics with diurnal cycles in most stations peak from afternoon to evening (i.e., 1200-2000 LST), but one exception is Duchang site, where the diurnal cycle peaks in the morning (i.e., 1000 LST). Moreover, the harmonics with $12 \mathrm{~h}$ cycle (semidiurnal cycle) have the relatively uniform amplitude of about $0.2 \mathrm{~mm}$, but their variance contributions show uneven distribution, with the contributions of about or above $50 \%$ in PL and Nanchang city (the semidiurnal cycles peak about 0000 LST or 1200 LST) and below $30 \%$ (or even $10 \%)$ in other areas. The preliminary diagnosis analysis shows that the diurnal variation of the low-level (below $850 \mathrm{hPa}$ ) air temperature (increasing after the sunrise, decreasing after the sunset, and peaking around 1400-1800 LST) may be responsible for the diurnal cycle. Moreover, in PL (Duchang and Poyang) and Nanchang city, the effects (heating or cooling) of lake and urban, the diurnal variation of the $10 \mathrm{~m}$ wind over PL, and the acceleration of PL on overlying air also contributed to the diurnal variation of PWV.

\section{Introduction}

Water vapor is an important part in the atmosphere. It is not only a necessary condition for precipitation but also an important indicator of climate variation [1]. Besides, water vapor also plays an important role in atmospheric radiation and water cycle [2]. The traditional method to detect water vapor in the atmosphere is mainly based on the water vapor sensor equipped on the sounding balloon (the traditional surface water vapor sensor cannot obtain the high-level water vapor information). However, the sounding observations have relatively low spatial-temporal resolution. In China, the spatial and temporal resolutions of sounding data are about $250 \mathrm{~km}$ and about $12 \mathrm{~h}$ [0800 local solar time (LST) and 2000 LST], respectively. With the relative large spatial and temporal variation of water vapor in atmosphere, the sounding data cannot satisfy the requirement to study the spatial and temporal variations of water vapor [2]. Recently, with the development of Global Positioning System (GPS) remote sensing technology, the precipitable water vapor (PWV) in atmosphere (i.e., the water vapor content in the whole atmospheric column) can be retrieved by calculating the delay of GPS satellites signals through GPS processing software, and the delays are induced by the atmospheric refraction, which is closely related to water vapor in atmosphere $[3,4]$. The PWV retrieved by GPS is well-known GPS PWV, which is not affected by the precipitation, clouds, aerosols, and so forth. Moreover, it has the characteristics of all-weather observation, high spatial-temporal resolution, and low cost $[5,6]$. More importantly, the GPS PWV has 
high accuracy. By comparison with the sounding PWV, the root mean square error is generally less than $3 \mathrm{~mm}[7,8]$, and the correlation is usually more than 0.95 [2].

The diurnal variation of water vapor in atmosphere is closely related to moist convection, precipitation, convergence of near-surface winds, surface evaporation, etc. $[2,9,10]$. The diurnal variation of PWV at some areas in the world has been revealed. For example, Dai et al. [2] investigated the diurnal variation of PWVs at 54 GPS stations in the United States during 1996-2000 and found that GPS PWVs over most of the stations had significant (the variance contribution to subdaily variation is more than $50 \%$ ) diurnal cycle (the period of $24 \mathrm{~h}$ ) signals with an amplitude of 1.0-1.8 mm during summer, and, in other seasons, the signals of diurnal cycle are reduced. $\mathrm{Ma}$ et al. [11] diagnosed the diurnal variation of PWV in eastern Tibet in summer and indicated that the diurnal cycle had the main (variance more than 50\%) signals of diurnal variation of PWV, while the half-daily ( $12 \mathrm{~h}$ ) cycle had some contribution. In Qilian Mountains, the PWV in summer has also obvious diurnal variation feature, which is mainly comprised of diurnal cycle and semidiurnal cycle, and in days without precipitation the diurnal cycle dominates the diurnal variation of PWV, while the diurnal cycle and semidiurnal cycle are important in days with precipitation [12]. In Lhasa valley, the diurnal variation of PWV is also mainly composed of diurnal cycle and semidiurnal cycle, and these cycles are the strongest in summer [12]. Besides, Liu and Liu [13] discovered that the minimum of GPS PWV over Beijing is presented in 0800-1200 LST, while the maximum occurred during 0100-0300 LST. Fu et al. [14] claimed that the GPS PWV over Hubei is bottomed during 0000-0600 LST and peaked at about 1800 LST. The diurnal variation of GPS PWV over Dalian is somewhat different, with the maximum in about 1600 LST and the minimum in about 2200 LST [15].

Poyang Lake (PL) is the largest freshwater lake in China. It is also a seasonal lake. In summer (July-August), the coverage of PL peaks about $3800 \mathrm{~km}^{2}$ area, with a $130 \mathrm{~km}$ length, an average of $30 \mathrm{~km}$ width (the maximum width is approximately $75 \mathrm{~km}$ ), and a mean depth less than $6 \mathrm{~m}$ $[16,17]$. Due to the difference of specific heat capacity between land and water, PL has an obvious influence on local weather and climate, especially at the diurnal change. In summer, PL is a heat source in nighttime and has a significant heating effect on the surrounding air, while it is a cold source in daytime with an obvious cooling effect [18]. With the significant diurnal variation of lake-land temperature difference, there is distinct land-lake breeze over PL and this land-lake breeze is strong in summer [19]. Besides, Fu et al. [20] indicated that the PL is conducive to weakening the crossing convective storm in noontime in summer. PL is a large body of water, and it can swap the water vapor with the overlying air through latent heat flux [21], finally affecting the water vapor over PL and its neighborhood [22].

$\mathrm{PL}$ is located in the East Asian summer monsoon region. Here, the western Pacific subtropical high (WPSH) is an important system [23], which is closely associated with the timing and spatial distribution of the summer climate in China $[24,25]$. In general, the ridge line of the WPSH gradually moves northward since spring and arrives at $27^{\circ} \mathrm{N}$ or further north after late June, and then it fluctuates around $27-32^{\circ} \mathrm{N}$ during midsummer (July-August) [25]. Finally, in early September, the WPSH rapidly withdraws southward with the ridge line at south of $27^{\circ} \mathrm{N}$ [25]. Clearly, the PL (about $29^{\circ} \mathrm{N}$ ) is located within the main body of WPSH during midsummer and controlled by sunny, hot, and dry weather. Therefore, in the midsummer (PL has the largest water coverage) with the hot, dry, and sunny weather, the exchange of water vapor between PL and overlying air should be strong. Also, Wang et al. [26] confirmed that the latent heat flux over PL is the maximum in the summer based on the turbulent flux observations.

What are the characteristics of the diurnal variations of PWV over PL? Are the diurnal variations of PWV at stations close to PL the same as those at stations far away from PL? In order to answer these questions, the GPS PWV data at 18 stations around PL in midsummer (the water vapor exchange between lake and overlying air is the largest) have been investigated in this paper. Section 2 describes data and its processing. Section 3 presents the climatology of GPS PWV over PL. The diurnal variation features are depicted in Section 4, and conclusions are given in Section5.

\section{Data and Processing}

In 2009, Jiangxi Meteorological Bureau and Jiangxi Surveying and Mapping Bureau jointly built 62 ground-based GPS observation stations, and these GPS stations are installed in the meteorological observation sites [27]. In the neighborhood of PL, there are 18 ground-based GPS stations (Figure 1). The ground-based GPS stations have been operational since 2009, collecting satellite pseudorange, carrier phase, navigation file, and other information with sample frequency of $15 \mathrm{~s}$ or $30 \mathrm{~s}$. However, some ground-based GPS stations were relocated and revamped before 2015 [28]. Therefore, in this paper, the ground-based GPS data from 2015 to 2018 are used, and these data are obtained from Jiangxi Meteorological Administration (JMA) through the Intranet of JMA (i.e., http://10.116.89.55/cimissapiweb/). Besides, the $2 \mathrm{~m}$ air temperatures at the 18 GPS stations (obtained from the JMA) and the ECMWF ERA5 reanalysis data (obtained form https://climate.copernicus.eu/climatereanalysis) are also used in the paper.

Since the observed data (pseudorange, carrier phase, etc.) of ground-based GPS are not direct water vapor information, it is necessary to convert them into common PWV by using GPS professional processing software. GAMIT software (v10.6), which has been developed by Massachusetts Institute of Technology, Scripps Institution of Oceanography, and Harvard University, is used to retrieve PWV. In order to improve the accuracy of PWV, the weighted average temperature model improved by Shan et al. [29] based on the sounding data in Jiangxi (China) and zenith static delay model (Hopfield model) improved by Zou et al. [30] are introduced into the GAMIT software. Meanwhile, to further improve the accuracy of PWV, 4 long baseline international IGS tracking stations' (LHAZ, ULAB, PIMO, and CUSV) detected data are also introduced in the 


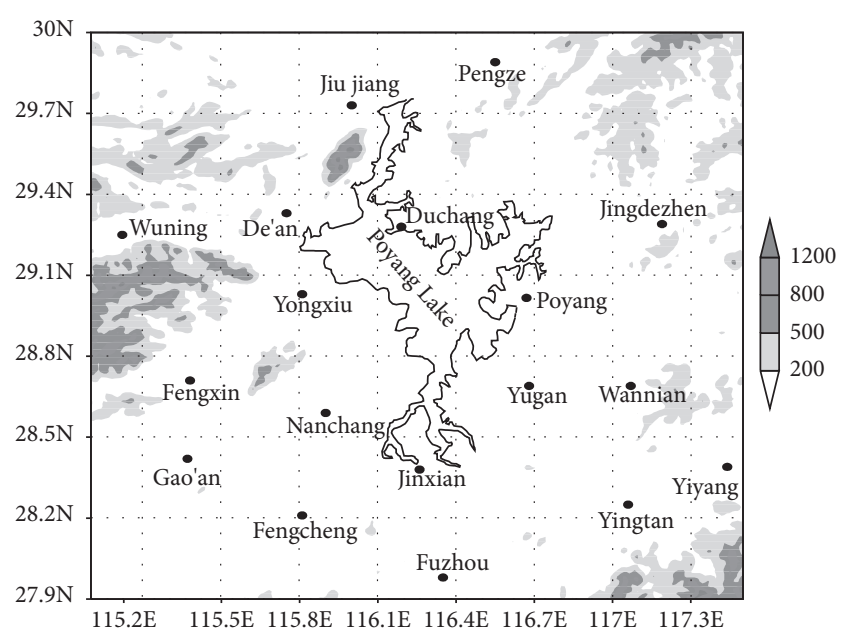

Figure 1: The GPS observation stations (solid circle) and the topography (shadow) (unit: $\mathrm{m}$ around $\mathrm{PL}$ ).

retrieval of GPS PWV. The data are obtained from http:// igscb.jpl.nasa.gov.

\section{The Climatology of GPS PWV over PL}

The validation on GPS PWV over Jiangxi, China, has been tested by Zou et al. [30]. The GPS PWVs in Nanchang site at UTC 0000 and 1200 LST during 2010, which were derived by the similar method in Section 2, were in good agreement with the sounding PWVs, with the temporal correlation of 0.97 and the mean bias of $0.37 \mathrm{~mm}$ [30]. This result provides evidence that the derived GPS PWV is reliable and can be applied in the climate studies. In order to further validate the GPS PWV around PL, a comparison of the GPS PWV and the sounding PWV in Nanchang site at UTC 0000 during June-August 2017 is performed. It is noted that only Nanchang site around PL has both GPS measurement and sounding measurement. Figure 2 compares the individual PWV measurements at UTC 0000 made using GPS method and sounding data. It can be seen that the GPS PWVs are in good consistency with the sounding PWVs, with the correlation of about 0.982 . The GPS PWV overestimates the PWV by about $1.5 \mathrm{~mm}$ (i.e., the mean bias), which is somewhat more than the statistics of 2010 [30]. The fact that the PWV data in this validation only includes the data during humid summer is responsible for that [2]. In the statistics of 2010, the PWV data also contains the dry winter data (the PWV may be smaller than $10 \mathrm{~mm}$ ). In fact, the mean bias of about $1.5 \mathrm{~mm}$ is equivalent to the relative bias of only about $3 \%$. These suggest that the GPS PWV has high accuracy and is suitable for studying the diurnal variations.

The monthly GPS PWV over PL averaged from 2015 to 2018 shows that the GPS PWV rapidly increases before June while it sharply decreases after August, and the maximum (minimum) is presented in July (December) with about 55 (15) $\mathrm{mm}$ (Figure 3(a)). In fact, the change of GPS PWVs between June and August is very slight, with the variation below $2 \mathrm{~mm}$ per month (Figure 3(a)). This is consistent with the monthly variations of GPS PWV at Ganzhou [31] and is

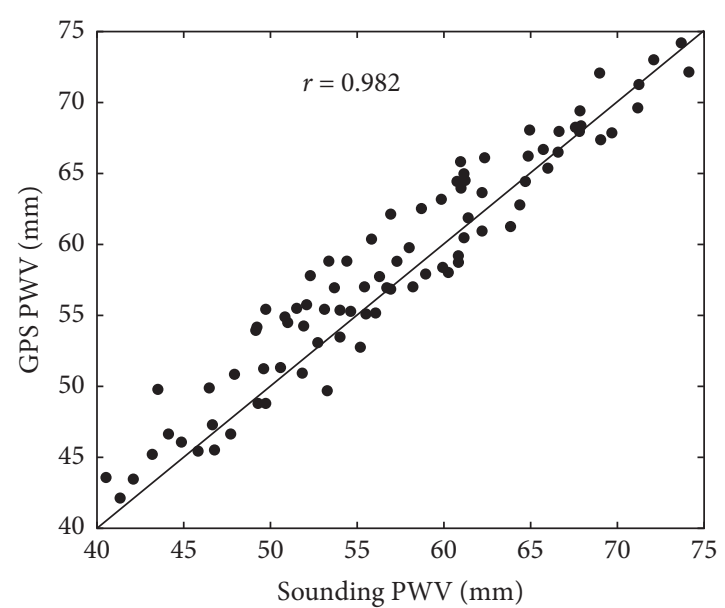

FIgUre 2: The scatterplots of PWV (mm) at UTC 0000 derived from GPS and sounding data at Nanchang site for June-August 2017. $r$ is a correlation coefficient.

slightly different from that in Beijing, in which the GPS PWV in June is obviously smaller than those in July and August [13]. The fact that the East Asian summer monsoon gradually moves northward before about mid-August is responsible for the difference in PWV between PL and Beijing because the East Asian monsoon can carry a big amount of water vapor [32]. In the spatial distribution of GPS PWV at midsummer (July-August), the large values (more than $56.6 \mathrm{~mm}$ ) are mainly situated over PL and Nanchang (the capital of Jiangxi Province in China) which is located to southwest of PL. The maximum of GPS PWV is not located at PL or its vicinity but at Nanchang city (Figures 1 and 3(b)). This may be induced by the heat island effect of Nanchang city [33] because high surface temperature can enhance surface evaporation and high air temperature is favorable for accommodating more water vapor.

Figure 3(b) also depicts the spatial distribution of the diurnal variation of the absolute GPS PWV (i.e., the maximum of GPS PWV minus the minimum). It is clear that the diurnal variations of the absolute GPS PWV are small over PL with the value less than $1 \mathrm{~mm}$, while the large diurnal variations are located outside of PL with the value more than $2 \mathrm{~mm}$. It is very interesting that the region with small diurnal variation of the absolute GPS PWV is just overlapping the area with large value of GPS PWV.

\section{Diurnal Analysis}

4.1. Analysis Method. The hourly mean GPS PWVs in individual stations around PL are first made by averaging the hourly data in midsummer during 2015-2018. It is noted that, in order to preserve the integrity of diurnal variation of GPS PWV data, the days with more than one-fourth of the observations missing are excluded. Then the hourly anomalies are obtained by removing the daily mean. With relatively short record and many missing gaps, Dai et al. [2] indicated that the above method for deriving the mean diurnal anomalies worked best for GPS PWV data compared to other methods (including high-pass filtering). 


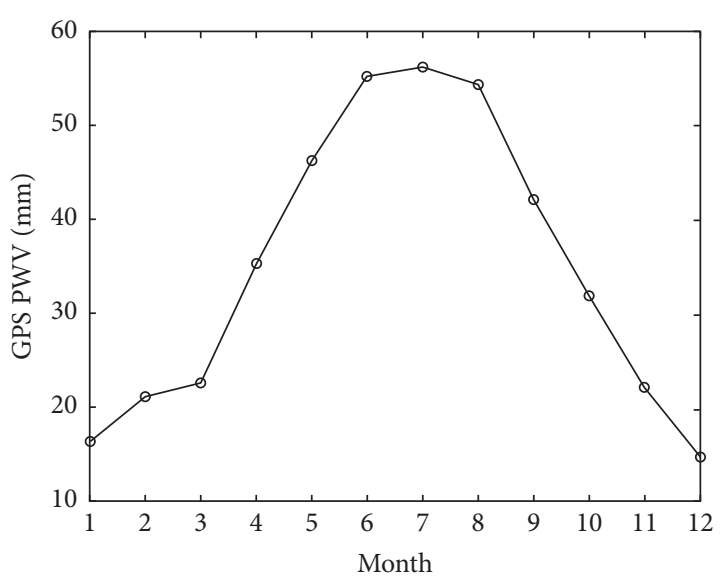

(a)

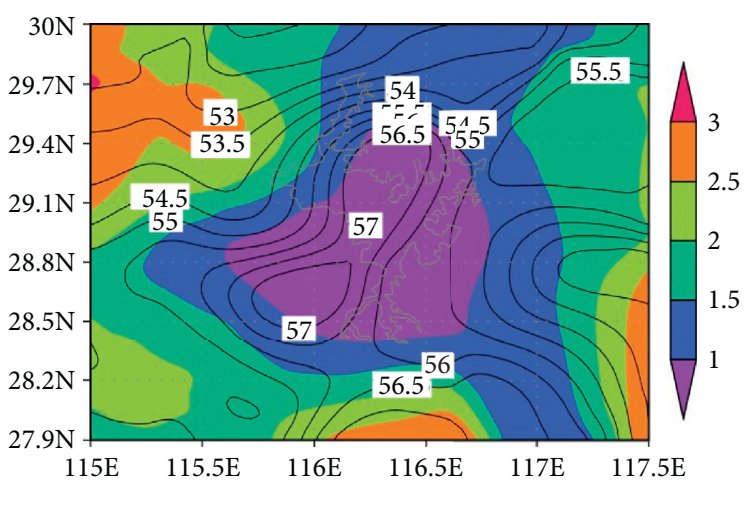

(b)

Figure 3: (a) The monthly averaged GPS PWV (mm) over PL from 2015 to 2018. (b) The spatial distribution of GPS PWV (solid lines) and the diurnal variation of the absolute value of the PWV (shadow, unit: $\mathrm{mm}$ ) over PL at midsummer (July-August).

Harmonic analysis can extract the known periodic signals from an irregular variation series, and then the periodic signals can be quantitatively described by amplitude, phase, and variance contribution. In view of these advantages, recently, harmonic analysis has been widely used to analyze the diurnal variation characteristic of a meteorological variable. For example, Dai et al. [2], Liang et al. [12, 34], and $\mathrm{Ma}$ et al. [11] used it in studying the diurnal variation characteristics of GPS PWV in different regions. Therefore, the method of harmonic analysis is also selected to study the diurnal variation of GPS PWV over PL in the current paper. The harmonic analysis [2] can be expressed as

$$
\begin{aligned}
P W\left(t_{1}\right) & =P W_{0}+\sum_{n=1}^{4} S_{n}\left(t_{1}\right)+R, \\
S_{n}\left(t^{\prime}\right) & =A_{n} \sin \left(n t^{\prime}+\sigma_{n}\right)=a_{n} \cos \left(n t^{\prime}\right)+b_{n} \sin \left(n t^{\prime}\right),
\end{aligned}
$$

where $S_{n}(n=1,2,3$, and 4$)$ denotes harmonics with periods of $24,12,8$, and 6 hours, respectively. $t^{\prime}$ is time with expression in degrees or radians (i.e., $t=2 \pi t^{\prime} / 24$, where $t$ is time in hours), and $\mathrm{PW}_{0}$ is the daily mean value. $R$ is the residual. $A_{n}$ is the amplitude, and $\sigma_{n}$ is the phase that can be easily calculated using $\sigma_{n}=\pi / 2-2 \pi n t_{\max } / 24\left(t_{\max }\right.$ is the time when the maximum of $S_{n}$ first appears). The calculations of $a_{n}$ and $b_{n}$ in (2) are as follows [34]:

$$
\begin{aligned}
& a_{n}=\frac{2}{M} \sum_{t=1}^{M} y_{t} \cos \frac{2 \pi n}{M} t, \\
& b_{n}=\frac{2}{M} \sum_{t=1}^{M} y_{t} \sin \frac{2 \pi n}{M} t,
\end{aligned}
$$

where $M$ is sample size (24 in this study) and $y_{t}$ is the hourly anomaly series of GPS PWV. In order to assess the contribution of harmonics with different periods to hourly anomaly series of GPS PWV, the variance contribution $\left(V_{n}\right)$ is also used, and its expression is as follows [26]:

$$
V_{n}=\frac{M}{2} \frac{A_{n}}{\sum_{t=1}^{M}\left(y_{t}-\bar{y}\right)^{2}}
$$

where $\bar{y}=\sum_{t=1}^{M} y_{t} / M$ is the daily mean of GPS PWV.

4.2. Variance Contribution. The spatial distributions of variance contributions in harmonics with periods of 24 (diurnal cycle) and 12 hours (semidiurnal cycle) are shown in Figure 4. It is clear that, in the diurnal cycle (Figure 4(a)), small variance contributions (less than 0.5 ) are located over PL and Nanchang city, which just coincides with the area of large GPS PWV (Figure 3(b)). In the other areas (except for Nanchang and $\mathrm{PL}$ ), the variance contributions of diurnal cycle are almost more than 0.8 (Figure 4(a)). Interestingly, the spatial distribution of variance contribution with semidiurnal cycle (Figure 4(b)) is just opposite to that of diurnal cycle (Figure 4(a)), with the large variance contribution (more than 0.3 or even 0.6 ) in PL and Nanchang city and the small (less than 0.3 or even 0.1 ) variance contribution in other areas. Moreover, the cumulative variance contributions of diurnal cycle and semidiurnal cycle are more than 0.8 in the whole region (not shown). This indicates that the diurnal cycle and semidiurnal cycle dominate the diurnal variation of GPS PWV over PL and its neighborhood, and, more specifically, in PL and Nanchang city, both cycles play important roles (the contribution of semidiurnal cycle is slightly more than that of diurnal cycle), while the diurnal cycle is dominant in other areas.

4.3. Amplitude. It can be clearly seen from Figure 5(a) that the spatial distribution of the amplitude of harmonic with diurnal cycle is quite analogue to that of variance contribution (Figure 4(a)). In areas far away from PL (i.e., PL and its coast) and Nanchang city, the amplitudes are about $0.9 \mathrm{~mm}$, similar to that in Qinghai-Xizang Plateau [11] and slightly smaller than that in the United States [2]. Importantly, over PL and Nanchang city, the amplitudes of harmonics with diurnal cycle are smaller than $0.3 \mathrm{~mm}$ or even 


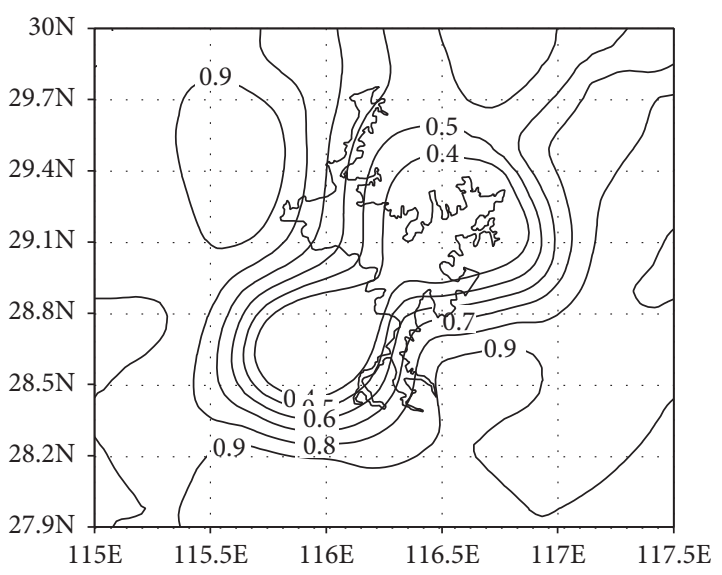

(a)

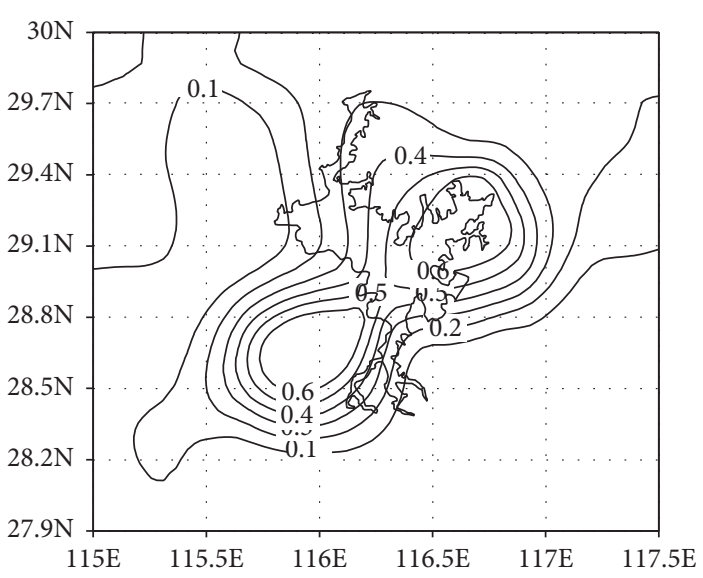

(b)

Figure 4: The variance contributions of (a) diurnal (24 hours) cycle and (b) semidiurnal (12 hours) cycle.

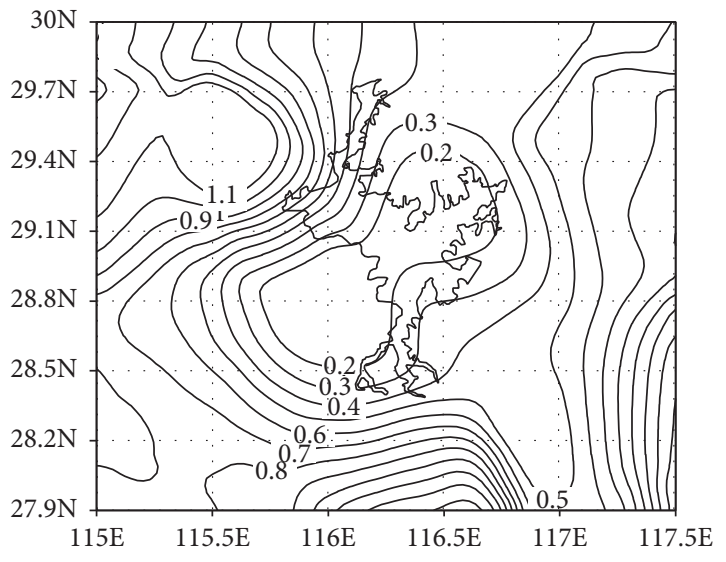

(a)

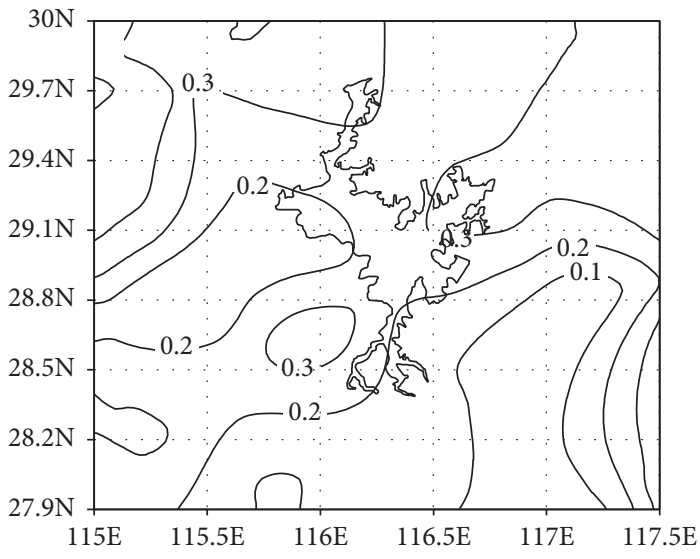

(b)

FIGURE 5: The amplitudes of (a) diurnal (24 hours) cycle and (b) semidiurnal (12 hours) cycle.

$0.2 \mathrm{~mm}$. This further suggests that the harmonics with diurnal cycle are relatively weak (intense) in PL and Nanchang city (elsewhere). Unlike that of the harmonics with diurnal cycle, the amplitude of harmonics with semidiurnal cycle distributes relatively homogeneously, ranging from $0.1 \mathrm{~mm}$ to $0.3 \mathrm{~mm}$, with about $0.25 \mathrm{~mm}$ over PL and its surrounding areas. As can be seen from the comparison of Figures 5(a) and 5(b), the amplitudes of the harmonics with diurnal and semidiurnal cycles over PL and Nanchang city are commensurate, while those with diurnal cycle in other areas are obviously large. This is in accordance with the distributions in variances of the harmonics with diurnal and semidiurnal cycles (Figure 4 ).

4.4. Phase. Figure 6(a) shows the distribution of the phase (i.e., the occurrence time of maximum value) of the harmonics with diurnal cycle. It can be seen that over the PL and its surrounding areas the harmonics with diurnal cycle peak from 1200 LST to 2100 LST (i.e., from midafternoon to evening). One exception is the Duchang site, where the maximum of the harmonics with diurnal cycle presents at 1000 LST (i.e., morning). Moreover, the harmonics with semidiurnal cycle usually peak at night (2300-0400 LST) (Figure 6(b)). Here, the time smaller than 0 in Figure 6(b) represents 2300 LST. Importantly, it can be seen form Figure 6(b) that the semidiurnal cycles over PL and Nanchang (2300-0100 LST) peak earlier than over other areas (0100-0400 LST). It is noted that the second cycle of the semidiurnal harmonics over this region peaks around 11001600 LST, with the early peak at PL and Nanchang.

In order to describe the features of the harmonics with diurnal cycle and semidiurnal cycles over lake, urban, and rural areas more clearly, the diurnal GPS PWV anomaly and the fitted diurnal and semidiurnal harmonics over Duchang site (it is the closest to PL and may represent lake), Poyang site (it is also close to the PL, but the distance between the site and lake is only larger than that between Duchang and lake), Nanchang site (it is in the urban and may represent urban), and Fengxin site (it is less affected by lake and urban and may represent rural) are shown in Figure 7. In fact, other sites far away from PL and Nanchang city also can better 


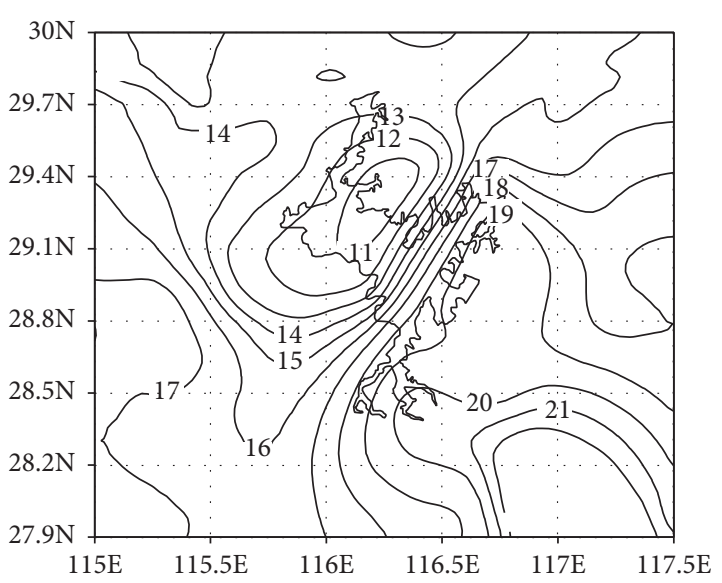

(a)

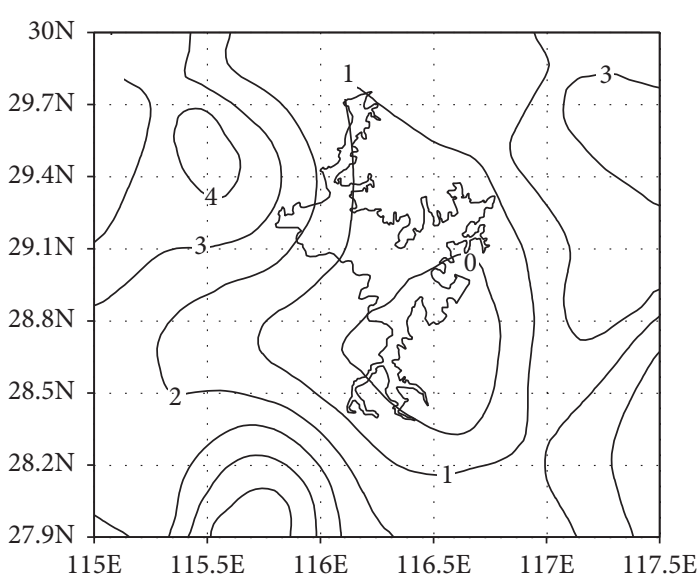

(b)

Figure 6: The time distribution of the first maximum of harmonics with (a) diurnal (24 hours) cycle and (b) semidiurnal (12 hours) cycle.

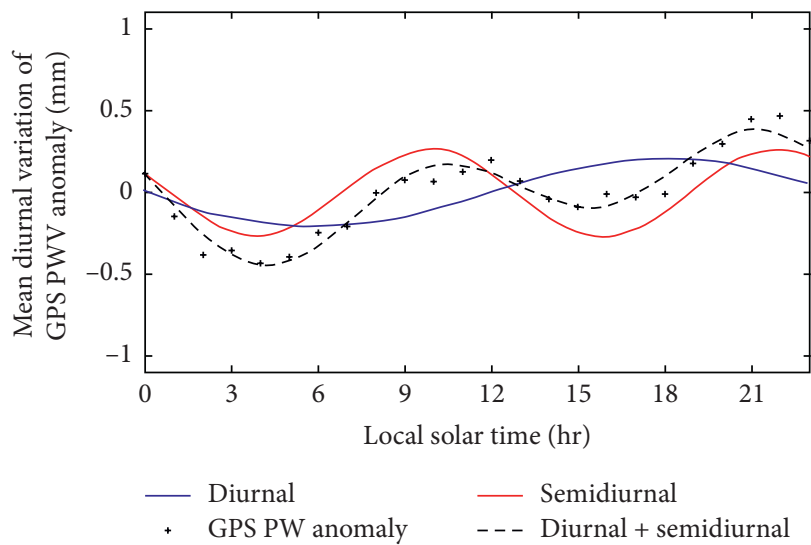

(a)

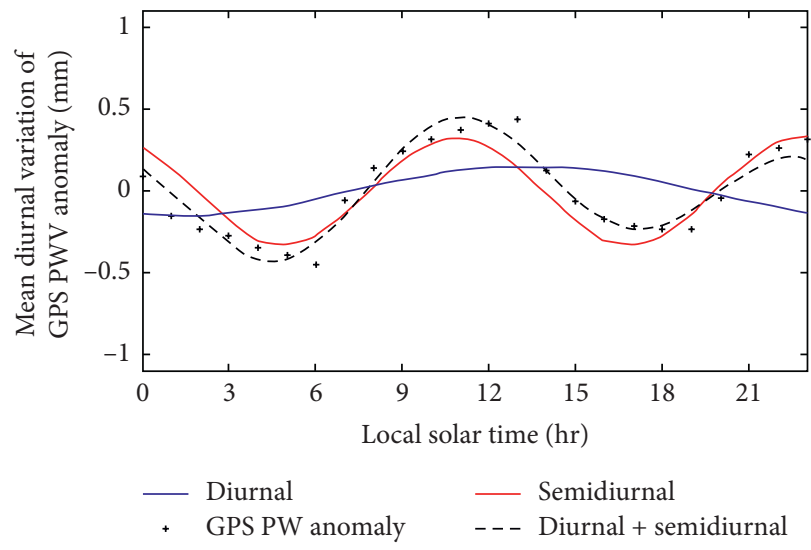

(c)

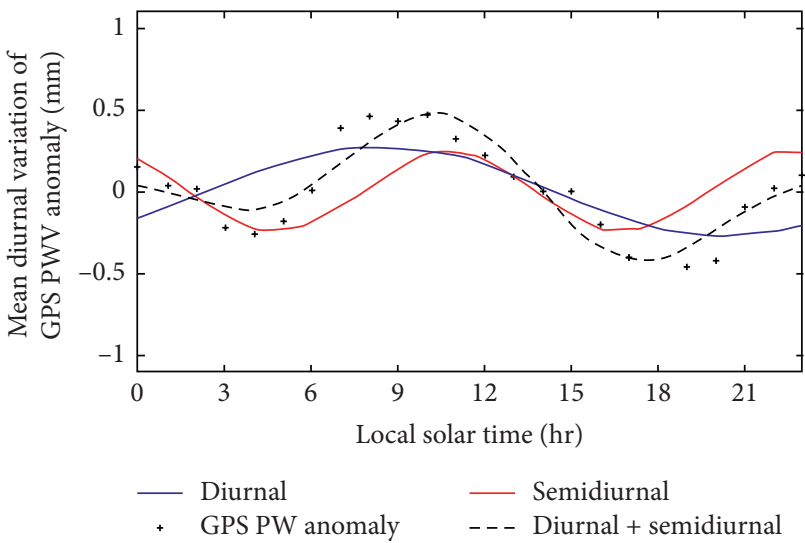

(b)

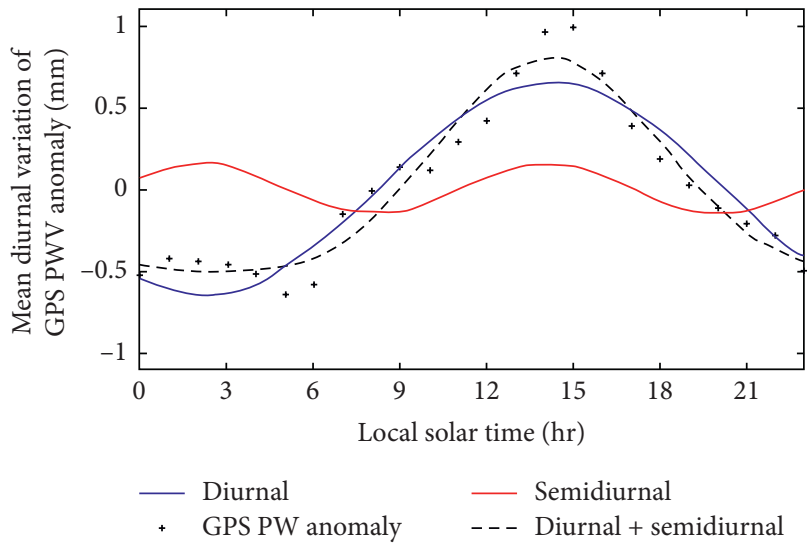

(d)

Figure 7: Mean July-August diurnal variations of GPS PWV anomaly ( $\mathrm{mm}$ ) and the fitted diurnal and semidiurnal harmonics at (a) Poyang, (b) Duchang, (c) Nanchang, and (d) Fengxin stations. Dashed curves are the sum of the fitted diurnal and semidiurnal harmonics.

represent the rural, and the diurnal variations of GPS PWV anomaly and the fitted diurnal and semidiurnal harmonics have similar features (not shown). It can be seen that the fitted diurnal harmonics and the semidiurnal harmonics can together represent the diurnal variations of GPS PWV anomaly very well (Figure 7). Over Poyang and Duchang (the two sites closest to lake) and Nanchang (in urban), the diurnal and semidiurnal harmonics are equivalent (Figures 7(a)-7(c)), while the diurnal cycle is the dominant in Fengxin (i.e., rural) (Figure $7(\mathrm{~d})$ ). This is consistent with the analysis of the variance contribution (i.e., Section 4.2). Figure 7 also shows that the semidiurnal harmonics over lake 
(Duchang and Poyang) and urban (Nanchang) are homologous, with similar phase (peaking at about 1000 and 2200 LST) and similar amplitude (about $0.25 \mathrm{~mm}$ ). However, the phases of the diurnal harmonics over lake and Nanchang are different; they peak at different times, around 1000-1800 LST (Figures 7(a)-7(c)).

\section{Discussion on the Causes of Diurnal Variations of GPS PWV}

There are many processes that can result in diurnal variations in atmospheric water vapor, including the surface evapotranspiration, the atmospheric low-level moisture convergence, the precipitation, and the large-scale vertical motion [2]. Besides, the low-level water vapor transport and the latent heat flux are also important processes affecting PWV. It is noted that the vertical mixing in the planetary boundary layer (the lowest $1-2 \mathrm{~km}$ ) only affects the vertical distribution of water vapor but does not affect the value of PWV [2].

Figure 8(a) depicts the diurnal variations of the mean temperature (averaged from 2015 to 2018) at different height over PL [i.e., the grid of $\left(116.25^{\circ} \mathrm{E}, 29^{\circ} \mathrm{N}\right)$ ] during July-August based on ECMWF ERA5 reanalysis data. It is clear that the air temperatures below $850 \mathrm{hPa}$ (especially below $925 \mathrm{hPa}$ ) increase after the sunrise (about 0600 LST), with peak around 1400-1800 LST, and decrease after the sunset (about 1900 LST), with bottom around 0300-0900 LST. The high air temperature in low level (including near surface) not only enhances the evapotranspiration of the surface but also enlarges the saturated water vapor content of low-level air, converting part of the low cloud (hydrometeor) into water vapor. This is conducive to increasing the PWV. Conversely, the low air temperature in low level (including near surface) reduces the evapotranspiration and the saturated water vapor content, decreasing the PWV. Therefore, the diurnal variation of the low-level air temperature is conducive to increasing (decreasing) the PWV during 1400-1800 (03000900) LST. This is just consistent with the diurnal variation of the PWV at Fengxin (which is less affected by the lake and urban) (Figure $7(\mathrm{~d})$ ), indicating that the diurnal variation of the low-level air temperature (which is in fact induced by solar radiation) is dominant to affect the PWV. In fact, the amplitude differences at different stations in Figure 3(b) and Figure 5(a) may also be induced by the different diurnal variation of low-level air temperature in different stations. Over PL and Nanchang, the diurnal variation of air temperature is obviously smaller than that over outside the PL and Nanchang (not shown). It is noted that, in Figure 8(a), the slight increase (decrease) of air temperature below $925 \mathrm{hPa}$ at about 0500 (1600) LST (i.e., the dashed lines in Figure $8(\mathrm{a})$ ) may be induced by the heating (cooling) of the underlying PL.

Near-surface winds are important factors to influence the water vapor transport (because the water vapor mainly resides in the low level) and the latent heat flux (which is proportional to the $10 \mathrm{~m}$ wind speed). Figure 8(b) (arrows) depicts the diurnal variations of the $10 \mathrm{~m}$ winds over PL (i.e., the grid of $\left(116.25^{\circ} \mathrm{E}, 29^{\circ} \mathrm{N}\right)$ in ERA5 reanalysis data). It is clear that the wind directions over PL rotate clockwise with time, with easterly wind at 0000 LST. In the morning (i.e., 0700-1200), the winds over PL convert to southerly wind, and the speed peaks at about 0900 LST (Figure 8(b)). The winds over PL shift to northerly wind during 1500-1800 LST with the speed peaks at about 1700 LST and then turn to easterly wind (Figure 8(b)). Since Duchang (the only site where the GPS PWV peaks in the morning) is located at the north shore of PL (Figure 1), the near-surface air over Duchang mainly comes from PL in the morning (southerly). Meanwhile, the large speed of wind over PL at about 1000 LST can strengthen the pumping of water vapor from underlying water by increasing the latent heat flux and then increases the PWV over Duchang by the water vapor transport. Clearly, the large southerly wind over PL at about 1000 LST is an important factor causing the GPS PWV in Duchang to peak at about 1000 LST. Besides, Figure 8(b) also shows that the $10 \mathrm{~m}$ meridional wind over PL is distinctly larger than that over Nanchang during 0800-1100 LST (prevailing southerly winds) and 1600-1900 LST (prevailing northerly winds). In fact, this reflects the accelerated effect of water body on overlying air due to the small surface friction of lake. The acceleration of near-surface wind can also contribute to the increase of GPS PWV at Duchang in the morning because it can enhance the convergence of air (water vapor) at the north shore of PL. Therefore, the peak of GPS PWV at Duchang in the morning (about 1000 LST) may be jointly induced by the diurnal variation of wind over PL and the accelerated effect of lake on wind.

Under the background of the warming in the low-level air (which can not only enhance the evapotranspiration but also enlarge the saturated water vapor content, favoring the increase of PWV) during afternoon (Figure 8(a)), the PWVs should increase. But why does the PWVs over PL and NC decrease (i.e., why does the valley of semidiurnal cycle appear at afternoon) (Figure 7)? In order to address this question, the diurnal variations of mean vertical motion (omega) at different levels below $775 \mathrm{hPa}$ over PL are drawn in Figure 9(a). As can be seen, during 1000-1900 LST, the omegas over PL are persistently positive with the maximum of above $1.2 \mathrm{~Pa} \mathrm{~s}^{-1}$ at about $1400 \mathrm{LST}$, indicating obvious downward motion. The obvious descending motion is instrumental in accumulating dry air coming from high levels, resulting in the reduction of PWV over PL. It is noted that the time-height variations of mean omega over Nanchang are similar to those over PL (not shown). This behavior may be responsible for the decreases of the GPS PWVs and the semidiurnal harmonics over PL and Nanchang during afternoon (Figure $7(\mathrm{a})-7(\mathrm{c})$ ).

Why does the obvious downward motion appear over PL and Nanchang during afternoon? The other areas far away from PL and Nanchang city have no similar behaviors during afternoon (not shown). Is it related to the temperature effects of the PL and the Nanchang city urban conditions? At afternoon (about 1400 LST), in warm season (summer), the land temperature around PL is obviously larger than the lake temperature [18]. Then, the large landlake temperature difference (the land is warmer than lake) can produce the lake breeze with air flowing from lake to 


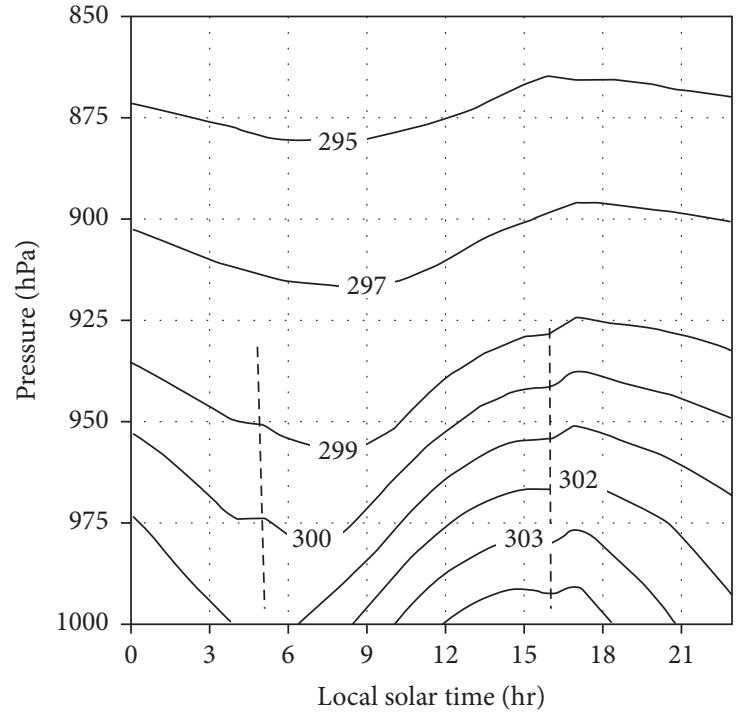

(a)

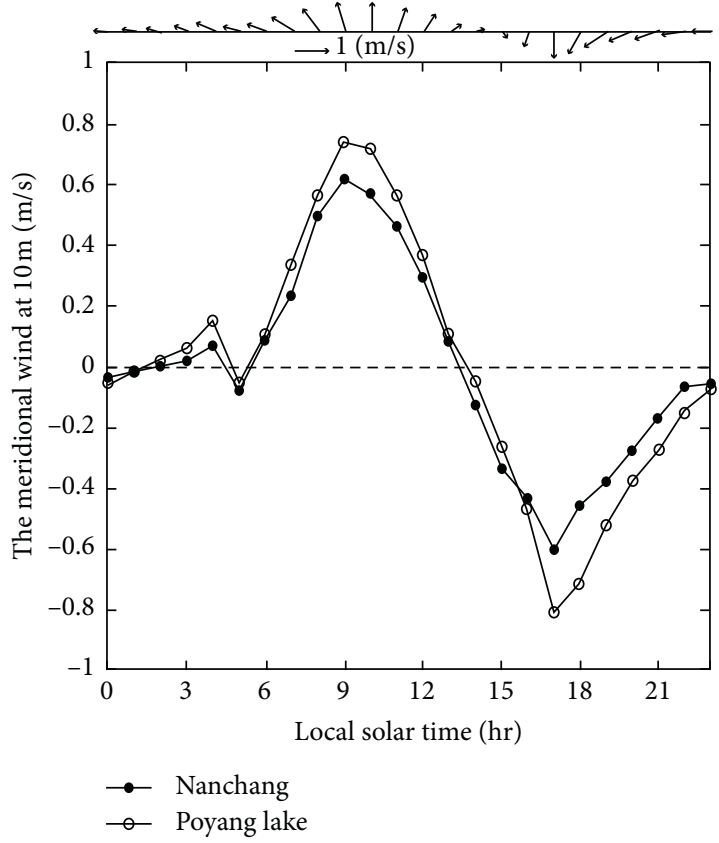

(b)

Figure 8: (a) The diurnal variations of air temperature (K) below $850 \mathrm{hPa}$ over PL and (b) the diurnal variations of $10 \mathrm{~m}$ meridional wind $\left(\mathrm{m} \mathrm{s}^{-1}\right.$ ) over PL and Nanchang and the $10 \mathrm{~m}$ wind (arrows, unit: $\mathrm{m} \mathrm{s}^{-1}$ ) over PL. It is noted that the grids of $116.25^{\circ} \mathrm{E}, 29^{\circ} \mathrm{N}$ and $116^{\circ} \mathrm{E}, 28.5^{\circ} \mathrm{N}$ represent PL and Nanchang in ERA5 reanalysis data, respectively.

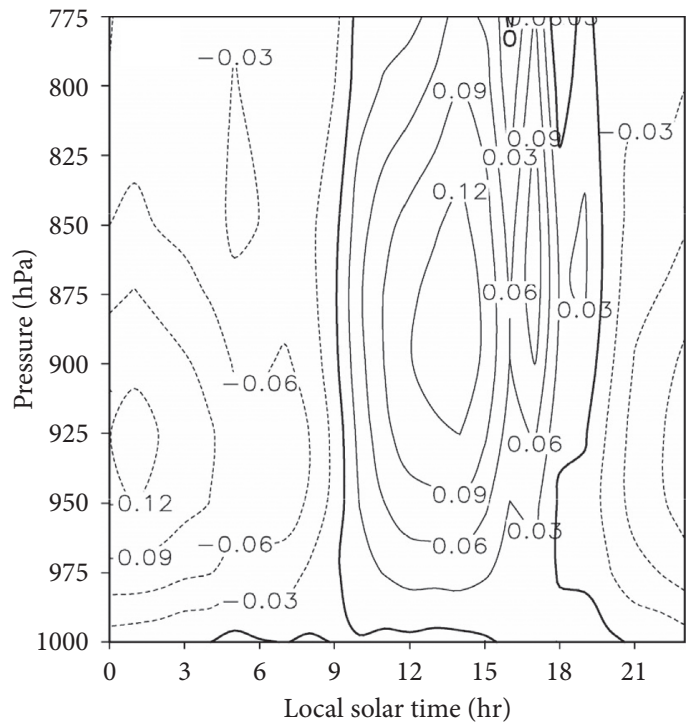

(a)

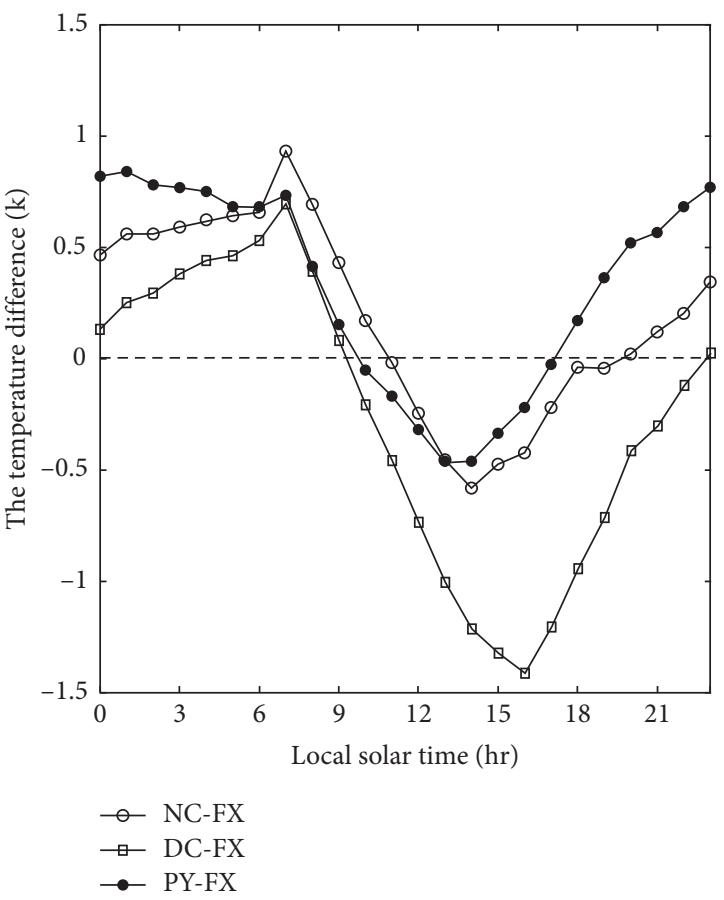

(b)

Figure 9: (a) The time-height variation of mean omega (lines, $\mathrm{Pa} \mathrm{s}^{-1}$ ) over PL (i.e., the grids of $116.25^{\circ} \mathrm{E}, 29^{\circ} \mathrm{N}$, and the thick lines represent the zero-velocity lines). (b) The diurnal variations of $2 \mathrm{~m}$ air temperature differences between Nanchang (NC), Duchang (DC), Poyang (PY), and Fengxin (FX).

nearby land $[19,35]$. This can result in descending motion over PL due to the compensation of air in high level to near surface, even maybe weakening the crossing storm [20]. In contrast, at night, the large lake-land temperature difference (the lake is warmer than land) can yield the land breeze with air flowing to lake from nearby land. The land breeze 
converges air over PL, resulting in ascending motion over PL, even maybe enhancing the crossing storm [36]. The evolution of the observed $2 \mathrm{~m}$ air temperature difference between Fengxin (far away from PL and Nanchang city) and Duchang (nearby PL) or Poyang (nearby PL) also shows that the sites nearby PL are cooler than the site far away from PL (Figure 9(b)), further confirming the PL as a cold source in daytime.

Figure 9(b)also shows that the observed $2 \mathrm{~m}$ air temperature differences between Fengxin and Nanchang are similar to those between Fengxin and Poyang. Why they are similar? There are two reasons affecting the $2 \mathrm{~m}$ air temperature of city. One is the city-heat-island effect, which can warm the city at nighttime in summer (it is similar to lake), resulting in large $2 \mathrm{~m}$ air temperature difference between Nanchang and Fengxin. The other one is that more condensation nuclei (e.g., aerosol and dust) reside over city due to the human activities [37]. The condensation nucleus can absorb and reflect the solar radiation (daytime), reducing the solar radiation reaching the surface [38]. This can decrease the $2 \mathrm{~m}$ air temperature in Nanchang during daytime, producing a negative air temperature difference between Nanchang and Fengxin. In fact, the evolutions of $2 \mathrm{~m}$ air temperature difference between Nanchang/Duchang and other rural sites far away from Nanchang and PL (Gao'an, Wannian, Jingdezhen, etc.) are similar to that between Nanchang/Duchang and Fengxin (not shown). Also, Xu et al. [12, 34] and Zhu et al. [39] indicate that the $2 \mathrm{~m}$ air temperature in urban of Shanghai was smaller than that in suburb during afternoon. Like the lake-effect temperature of PL, the city-effects temperature can also drive descending (ascending) motion in the afternoon (early morning), finally resulting in the decrease (increase) of GPS PWV over Nanchang (Figure 7(c)).

\section{Summary}

The hourly atmospheric precipitable water vapor (PWV) during 2015-2018 from the 18 ground-based GPS stations in the surrounding areas of Poyang Lake (PL), China, is retrieved by the GAMIT software developed by MIT. The monthly mean GPS PWVs (i.e., the PWV retrieved by GPS data) over PL show that the PWVs rapidly increase before June, while they sharply decrease after August, with the maximum (minimum) of 55 (15) $\mathrm{mm}$ at July (December). Besides, the changes of GPS PWVs during June-August are very slight, with the variation of less than $2 \mathrm{~mm}$ per month. The spatial distribution of the mean GPS PWVs during midsummer shows that, over PL (Duchang and Poyang, i.e., the two closest sites from PL) and Nanchang City (the capital of Jiangxi Province, located at about $30 \mathrm{~km}$ southwest of PL), the GPS PWVs are obviously larger than those over other areas. In order to study the diurnal variations of the GPS PWVs over PL and its surrounding areas, the $1 \mathrm{~h}$-averaged data of GPS PWVs at different ground-based stations are converted into diurnal anomalies by removing the daily mean, and then the harmonic analysis method is employed to research the diurnal variation.

Significant diurnal variations of GPS PWVs are found at the 18 ground-based GPS stations. The harmonics with $24 \mathrm{~h}$ cycle (diurnal cycle) over PL (Duchang and Poyang) and
Nanchang city have about 50\% (or even smaller than $50 \%$ ) variance contribution, with the amplitude of about $0.2 \mathrm{~mm}$, while those over other areas have above $70 \%$ (or even more than $80 \%$ ) variance contribution, with the amplitude of about $0.9 \mathrm{~mm}$. Besides, the harmonics with $24 \mathrm{~h}$ cycle in the surrounding areas of PL peak from the afternoon to the evening (i.e., 1200-2000 LST), except for the Duchang station at the north shore of PL, which peaks in the morning (i.e., 1000 LST).

The harmonics with $12 \mathrm{~h}$ cycle (semidiurnal cycle) over $\mathrm{PL}$ and its surrounding areas have relatively uniform amplitude of about $0.2 \mathrm{~mm}$, but their contributions to the subdaily variance are significantly diverse. In PL (Duchang and Poyang) and Nanchang city, the semidiurnal cycles account for about $50 \%$ (or even more than 50\%) of the variance contribution and peak at about 0000 LST or 1200 LST. However, in other areas, the semidiurnal cycles occupy less than $30 \%$ (or even less than 10\%).

The hourly mean temperatures (ECMWF ERA5 data) in different heights over PL during July-August show that the air temperatures below $850 \mathrm{hPa}$ increase after the sunrise (about 0600 LST), peak around 1400-1800 LST, decrease after the sunset (about 1900 LST), and bottom around 0300-0900 LST. The diurnal variation of air temperatures contributes to the diurnal cycle of PW. However, in PL and Nanchang city, the reasons to influence the diurnal variation are more complex. The peak of the $10 \mathrm{~m}$ southerly wind over PL at about 0900 LST modifies the diurnal variation of PWV at Duchang site at the north shore of PL, because it increases the PL moistened air transporting to Duchang. Besides, the acceleration of PL on overlying air increases the convergence of the near-surface air in Duchang at about 0900 LST, also favoring the increase of PWV. In addition, the cooling of the PL and Nanchang city (condensation nucleus absorbs and reflects the solar radiation) during afternoon can induce the remarkable downward motion, producing the decrease of PWV.

This study examined the diurnal variation of PWVs over PL and its surrounding areas, and the results suggest that the diurnal variations of PWV over PL and Nanchang city are similar, with the semidiurnal cycle ( $12 \mathrm{~h}$ cycle) accounting for about $50 \%$ of variance contribution. Some probable reasons affecting the diurnal variations of PWV are also discussed. Nevertheless, further analyses (such as the quantitative diagnostic analysis and numerical simulation) are needed in the future.

\section{Data Availability}

The data used to support the findings of this study are available from the corresponding author upon request.

\section{Conflicts of Interest}

The authors declare that they have no conflicts of interest.

\section{Acknowledgments}

This study was jointly supported by the National Natural Science Foundation of China (Grant nos. 41865003 and 
41765001) and Jiangxi Provincial Department of Science and Technology project (Grant no. 20171BBG70004).

\section{References}

[1] P. Zhai and M. Robert, "Atmospheric water vapor over China," Journal of Climate, vol. 10, no. 10, 1997.

[2] A. Dai, J. Wang, R. H. Ware et al., "Diurnal variation in water vapor over North America and its implications for sampling errors in radiosonde humidity," Journal of Geophysical Research: Atmospheres, vol. 107, no. D10, 2002.

[3] M. Bevis, S. Businger, T. A. Herring, C. Rocken, R. A. Anthes, and R. H. Ware, "GPS meteorology: remote sensing of atmospheric water vapor using the global positioning system," Journal of Geophysical Research, vol. 97, no. D14, pp. 15787-15801, 1992.

[4] G. Xu, R. Wan, W. Li et al., "Improvement on the method for estimating precipitable water from ground-based GPS," Torrential Rain and Disasters, vol. 28, no. 3, pp. 203-209, 2009, (in Chinese).

[5] Y. Zhao and S. Zhang, "Analysis of the characteristics of GPS perceptible water vapor in arctic yellow river station," Journal of Geodesy and Geodynamics, vol. 34, no. 5, pp. 139-143, 2014, (in Chinese).

[6] M. Zeng, B. Zhang, J. Zhou et al., "Quantitative evaluation for GPS/PWV data assimilation in heavy precipitation events," Journal of the Meteorological Sciences, vol. 34, no. 1, pp. 77-86, 2014, (in Chinese).

[7] J. Duan, M. Bevis, P. Fang et al., "GPS meteorology: direct estimation of the absolute value of precipitable water," Journal of Applied Meteorology, vol. 35, no. 6, pp. 830-838, 1996.

[8] C. Li, J. Mao, J. Li et al., "Total remote sensing water vapor of GPS," Science Bulletin, vol. 44, no. 3, pp. 333-336, 1999, (in Chinese).

[9] A. Dai and C. Deser, "Diurnal and semidiurnal variations in global surface wind and divergence fields," Journal of Geophysical Research, vol. 104, no. 109, p. 31, 1999.

[10] A. Dai, "Global precipitation and thunderstorm frequencies, II, Diurnal variations," Journal of Climate, vol. 14, pp. 112$1128,2001$.

[11] S. Ma, S. Zhou, S. Wang et al., "Diurnal variation characteristics of GPS-retrieved precipitable water vapor over mideast xizang in summer," Plateau Meteorology, vol. 35, no. 2, pp. 318-328, 2016, (in Chinese).

[12] H. Liang, J. Liu, R. Zhang et al., "Diurnal variations of atmospheric water vapor in Lhasa river valley," Advances in Water Science, vol. 21, no. 3, pp. 335-342, 2010, (in Chinese).

[13] D. Liu and X. Liu, "Variation features of atmospheric precipitable water vapor derived from groud-based GPS in beijing," Journal of Applied Meteorological Science, vol. 20, no. 3, pp. 346-353, 2009, (in Chinese).

[14] Z. Fu, R. Wan, S. Yu et al., "Analysis and application of ground-based GPS precipitable water vapor characteristics," Journal of the Meteorological Sciences, vol. 37, no. 4, pp. 553-560, 2017, (in Chinese).

[15] T. Huang, Z. Huang, J. Zhu et al., "Characteristics of precipitable water vapor based on ground-based GPS in Dalian," Journal of Meteorology and Environment, vol. 30, no. 2, pp. 45-50, 2014, (in Chinese).

[16] Y. Li, J. Yao, X. Zhang et al., "Study on the vertical stratification in Poyang Lake," Resources and Environment in the Yangtze Basin, vol. 26, no. 6, pp. 915-924, 2017, (in Chinese).

[17] D. Shankman, B. D. Keim, T. Nakayama, R. Li, D. Wu, and W. C. Remington, "Hydroclimate analysis of severe floods in
China's Poyang lake region," Earth Interactions, vol. 16, no. 14, pp. 1-16, 2012.

[18] J. Wan, D. Lv, and F. Liu, "Summer temperature field and its temperature effect in Poyang Lake," Quarterly Journal of Applied Meteorology, vol. 5, no. 3, pp. 374-379, 1994, (in Chinese).

[19] J. Cao, X. Liu, G. Li et al., "Analysis of the phenomenon of lake-land breeze in Poyang Lake area," Plateau Meteorology, vol. 34, no. 2, pp. 426-435, 2015, (in Chinese).

[20] M. Fu, Y. Zheng, H. Zou et al., "Analysis on weakening process of convective system passing over Poyang Lake in summer," Plateau Meteorology, vol. 32, no. 3, pp. 865-873, 2013, (in Chinese).

[21] J. Chen and J. Wang, "Diurnal cycles of the boundary layer structure simulated by WRF in beijing," Journal of Applied Meteorological Science, vol. 17, no. 4, pp. 403-411, 2006, (in Chinese).

[22] M. Yan, Y. Qian, and J. Liu, "Interdecadal variations of the western Pacific subtropical high and surface heat flux over East Asia and their relationship," ACTA Meteorological Sinica, vol. 69, no. 4, pp. 610-619, 2011, (in Chinese).

[23] M. J. Rodwell and B. J. Hoskins, "Subtropical anticyclones and summer monsoon," Journal of Climate, vol. 14, pp. 3192-3211, 2011.

[24] Y. H. Ding, “The summer monsoon in East Asia," Monsoons over China, vol. 35, 1994.

[25] D. Wei, L. Chongyin, and T. Yanke, "Variation features and the impact of the latitudinal position of the western Pacific subtropical high in summer," Climatic and Environmental Research, vol. 16, no. 3, pp. 255-272, 2011, (in Chinese).

[26] D. Wang, "Harmonic analysis of the annual march of precipitation over the main land of China," Geographical Research, vol. 2, no. 2, pp. 44-54, 1983, (in Chinese).

[27] H. Zou, J. Shan, S. Wu et al., "Using GAMIT to derivate the precipitable water (PW) of Jiangxi Province," Meteorology and Disaster Reduction Research, vol. 33, no. 3, pp. 56-60, 2010, (in Chinese).

[28] H. Zou, X. Yi, J. Shan et al., "The effect of approximate coordinates on GPS PWV," Meteorological Monthly, vol. 43, no. 12, pp. 1847-1553, 2017, (in Chinese).

[29] J. Shan, H. Zou, X. Liu et al., "Localization studies of Tm model in derivatiing the GPS/MET precipitable water over Jiangxi," Earth Interactions, vol. 35, no. 1, pp. 45-49, 2012, (in Chinese).

[30] H. Zou, J. Shan, S. Wu et al., "Improvement of GPS moisture solving method and the application to Typhoon induced heavy rainfall," Acta Scientiarum Naturalium Universitatis Sunyatseni, vol. 52, no. 6, pp. 17-25, 2013, (in Chinese).

[31] Z. Bin, Y. Wu, L. Qiu et al., "Variation characteristic and accuracy of perceptible water vapor from ground-based GPS remote sensing in Jiangxi," Plateau Meteorology, vol. 32, no. 5, pp. 1503-1509, 2013, (in Chinese).

[32] X. Lv, X. Zhang, and J. Chen, "The interdecadal variability of north-south movement of East Asian summer monsoon and its effect on the regional rainfall over China," Journal of Tropical Meteorology, vol. 27, no. 6, pp. 860-868, 2011, (in Chinese).

[33] X. Chen, X. Wen, and L. Guo, "Study on urban heat island effect in Nanchang based on landset 8 satellite images," Acta Agriculture Jiangxi, vol. 29, no. 3, pp. 103-108, 2017, (in Chinese).

[34] H. Liang, J. Liu, and Y. Chen, "Characteristics and cause of diurnal variation of precipitable water vapor derived from 
ground-based GPS in qilian Mountains in summer," Plateau Meteorology, vol. 29, no. 3, pp. 726-736, 2010, (in Chinese).

[35] W. J. Steenburgh, S. F. Halvorson, and D. J. Onton, "Climatology of lake-effect snowstorms of the great salt lake," Monthly Weather Review, vol. 128, no. 3, pp. 709-727, 2000.

[36] H. Zou, S. Zhang, Y. Liu et al., "Analysis of a convective storm crossing Poyang Lake in China," Journal of Meteorological Research, vol. 34, no. 3, pp. 529-545, 2020.

[37] W. Xu, H. Yang, S. Zhang et al., "Variations of the urban heat island effect in Shanghai," Journal of Tropical Meteorology, vol. 34, no. 2, pp. 228-238, 2018, (in Chinese).

[38] H. Wang, J. Huang, and C. Chen, "The influences of urban aerosols on solar radiation and their reflection in urban boundary layer temperature variation," ACTA Meteorological Sinica, vol. 51, no. 4, pp. 457-464, 1993, (in Chinese).

[39] J. Zhu, X. Tang, and H. Jiang, "The air temperature variation and heat island effect in urban area of Shanghai City," Plateau Meteorology, vol. 25, no. 6, pp. 1154-1160, 2006, (in Chinese). 